\title{
Jean Heidmann (1923-2000) and SETI
}

\author{
Régis Courtin
}

LESIA, CNRS \& Observatoire de Paris, 92195 Meudon, France
email: regis.courtin@obspm.fr

\begin{abstract}
Jean Heidmann (1923-2000) began his research career as a radio-astronomer in 1959 at Paris Observatory, investigating the structure of galaxies and the distance scale in the nearby universe. In the early 1980's, his scientific interest broadened to the search for extraterrestrial intelligence and he became a strong advocate of SETI, either from the ground or from space.
\end{abstract}

\section{Introduction}

Jean Heidmann was born May 181923 in Jeumont (Nord). In 1946, then a fresh graduate in engineering from Ecole Centrale, he joined the physics laboratory headed by Louis Leprince-Ringuet at Ecole Polytechnique. He was given the task of solving one of the burning questions in cosmic rays physics at the time, namely the emission of fast deutons in nuclear disintegrations generated by cosmic rays. Between 1948 and 1951, this project led him to the Wills Physics Laboratory in Bristol, where he worked under the supervision of Nevill Mott, and to the Laboratory of Nuclear Studies at Cornell University, where he worked for two years under the direction of Hans Bethe. In June 1951, he defended a PhD Thesis at Cornell, and another at Paris University in December. The members of his jury were no less than Louis de Broglie, Francis Perrin, and Louis Leprince-Ringuet, probably the top three French physicists at the time.

\section{Astronomer, science editor, communicator, and advocate of SETI}

Appointed "Maître de Recherches" at "Centre National de la Recherche Scientifique" (CNRS) in 1955, Heidmann continued working at Ecole Polytechnique for a few more years. In 1959, he was named "Astronome" and invited by Jean-François Denisse to join the radio-astronomy team at the Meudon branch of the Paris Observatory. The design of the Nançay Radio-Telescope was already well advanced. Starting in 1965, and through the 1970's, Heidmann and his colleagues worked with this powerful instrument to investigate the hydrogen content of galaxies as measured by the $21 \mathrm{~cm}$ line (Chamaraux, Heidmann \& Lauqué 1970, Balkowski et al. 1972). Using optical or UV telescopes as well, they also contributed to the multi-wavelength study of Markarian galaxies (Bottinelli et al. 1975), and to the determination of the Hubble constant (Heidmann 1977). Together with Italian astronomer C. Casini, he identified the so-called clumpy irregular galaxies (Casini \& Heidmann 1976).

Heidmann was one of the first editors-in-chief of the European journal Astronomy and Astrophysics from 1973 to 1979 . He was also very adept at communicating astronomy to students and to the public, either through books (Heidmann 1979, Heidmann 1980, Heidmann 1982, Heidmann 1986, Heidmann 1992, Heidmann 1998, Heidmann et al. 2000), numerous public conferences, or a radio program on the national network.

Towards the end of his career, his passion for SETI which started around 1982, became the main thrust behind his work. With François Biraud, and in collaboration with Jill 
Tarter and Samuel Gulkis, he carried out the first search programs in Europe using the Nançay radiotelescope. One such program consisted in using rotational frequencies of pulsars to select preferred search frequencies in the 1-10 GHz Galactic radio window (Heidmann, Biraud \& Tarter 1989), whereas another involved a small sample of newly discovered extrasolar planets (Biraud et al. 1997).

Even after his official retirement in 1993, Heidmann continued working on various aspects of SETI (Heidmann 1993, Heidmann 1994a) and was the driving force behind innovative SETI space concepts. For instance, in 1994, he proposed the establishment of a RFI-free site inside crater Saha, on the far side of the Moon (Heidmann 1994b). Until his death, he was a strong advocate of this proposal in various arenas (Heidmann 2000a, Heidmann 2000b). With Claudio Maccone, he also proposed to use the gravitational focusing effect of the Sun to detect extraterrestrial civilizations, and to study the Galactic center at high-gain (Heidmann \& Maccone 1994).

His international involvement was very strong: in 1990, he was the lead-organizer of the Third International Symposium on Bioastronomy held at Val-Cenis, France (Heidmann \& Klein 1991); within the International Astronautical Academy, he led the SETI Commitee and coordinated the "Lunar SETI Cosmic Study" started in 1998; within the International Astronomical Union, he was a member of the Organizing Committee of Commission 51 on Bioastronomy since 1988, and its Secretary since 1991.

Heidmann's convictions about the eventual success of SETI were so powerful that he dared propheticize that the "S" of SETI, after standing for "search", would one day mean "survey", then "study", and ultimately "sociology" of extraterrestrial intelligence.

\section{References}

Balkowski, C., Bottinelli, L., Gouguenheim, L., \& Heidmann, J. 1972 A 6 A 21, 303

Biraud, F., Heidmann, J., Tarter, J., \& Airieau, S. 1997 Proc. IAU Colloquium No. 161 (Bologna: Editrice Compositori), p. 689

Bottinelli, L., Gouguenheim, L., Heidmann, J., \& Duflot, R. 1975 A $\& A$ 41, 61

Casini, C. \& Heidmann, J. 1976, A\&A A, 47, 371

Chamaraux, P., Heidmann, J., \& Lauqé, R. 1970 A $\& A$ 8, 424

Heidmann, J. 1977 in: C. Balkowski \& B.E. Westerlund (eds.), Proc. IAU Colloquium No. 37 (Paris: CNRS), p. 487

Heidmann, J. 1979 Au delà de la Voie Lactée, un étrange Univers (Paris: Hachette)

Heidmann, J. 1980 Relativistic Cosmology: an introduction (Berlin: Springer-Verlag)

Heidmann, J. 1982 Extragalactic Adventure (Cambridge: Cambridge University Press)

Heidmann, J. 1986 L'odyssée cosmique (Paris: Denoël)

Heidmann, J. 1992 La vie dans l'Univers (Paris: Fayard)

Heidmann, J. 1993 in: F. Bertola \& U. Curi (eds.), The Anthropic Principle. Proc. Second Venice Conference (Cambridge: Cambridge University Press), p. 111

Heidmann, J. 1994a J. Brit. Interplan. Soc. 47, 71

Heidmann, J. 1994b Acta Astronaut. 32, 471

Heidmann, J. 1998 Intelligences extraterrestres (Paris: Odile Jacob)

Heidmann, J. 2000a Acta Astronaut. 46, 661

Heidmann, J. 2000b Adv. Space Res. 26, 371

Heidmann, J., Biraud, F., \& Tarter, J. 1989 Proc. 40th Int. Astron. Congress, Malaga, Spain

Heidmann, J. \& Klein, M. J. (eds.) 1991 Bioastronomy. The Search for Extraterrestrial Life, Lecture Notes in Physics 390 (Berlin: Springer-Verlag)

Heidmann, J. \& Maccone, C. 1994 Acta Astronaut. 32, 409

Heidmann, J., Vidal-Madjar, A., Reeves, H., \& Prantzos, N. 2000 Sommes-nous seuls dans l'Univers? (Paris: Fayard) 